\title{
Method development for simultaneous detection of ferulic acid and vanillin using high-performance thin layer chromatography
}

\author{
Swarali S Hingse, Shraddha B Digole and Uday S Annapure*
}

\begin{abstract}
Background: A simple, accurate, and reliable high-performance thin-layer chromatography (HPTLC) method was developed for separation and detection of ferulic acid and vanillin.

Methods: Separation of ferulic acid and vanillin was carried out on $20 \times 10 \mathrm{~cm}$ thin layer chromatography (TLC) plates using mobile phase containing toluene/1, 4-dioxan/acetic acid in the ratio 9:2.5:0.4 ( $/ / \mathrm{v})$. The FA and vanillin were scanned at 320 and $312 \mathrm{~nm}$, respectively. Method was validated for linearity, accuracy, precision, robustness, limit of detection, limit of quantification, and specificity.

Results: Retention factor (Rf) obtained for ferulic acid and vanillin was 0.48 and 0.56 , respectively. The correlation coefficients, 0.9975 and 0.9991 with an average recovery of $98.77 \%$ and $98.45 \%$ obtained for ferulic acid and vanillin respectively by this method were satisfactory.

Conclusion: The optimized method was found to be efficient, precise, accurate, specific, and economic. Therefore, the method would be useful for both qualitative and quantitative routine analysis in pharmaceutical, food industry, and research laboratories.
\end{abstract}

Keywords: Ferulic acid; Vanillin; High-performance thin layer chromatography (HPTLC); Simultaneous detection

\section{Background}

Aromatic compounds are present in natural sources with substantial combinations which are directly responsible for its odor and sensitivity. They can be categorized as volatile organic compounds like aldehydes, alcohols, ketones, esters, lactones, and terpenes (Raisi et al. 2008). They are known to be precursors for the production of numerous products employed in the food, pharmaceutical, and chemical industries and are present at very low concentrations in natural sources. According to US and European legislations, synthetic flavor production is not considered as natural. Alternatively, biotechnology offers microorganisms as production hosts for different types of aromatic compounds in industrial fermentative processes (Lomascolo et al. 1999). The most intensively studied biotransformation using microorganisms is the bio conversion of ferulic acid (FA) to produce natural vanillin (Priefert et al. 2001).

\footnotetext{
* Correspondence: udayannapure@gmail.com

Food Engineering and Technology Department, Institute of Chemical Technology, Nathalal Parekh Marg, Matunga, Mumbai - 400019, India
}

FA is an important precursor of vanillin that is available in abundance in plant cell walls linked to polysaccharide by an ester or ether bonds (Xu et al. 2005). FA is a potent antioxidant because it effectively scavenges free radicals and even possesses antimicrobial properties by preventing the lipid peroxidation caused by microbes (Graf 1992). Moreover, it is used in cosmetics for the photo protection of skin and in protection against various inflammatory diseases.

Vanillin is widely used in food industry as a flavoring agent but also has applications in some fragrances and pharmaceuticals (Priefert et al. 2001). It is also known to possess anti-metastatic, anticancer (Ho et al. 2009) and anti-inflammatory (Wu et al. 2009) activities. It exhibits antimicrobial properties due to its phenolic nature and hence used to develop antimicrobial films used in packaging of bakery products (Rakchoy et al. 2009).

FA and vanillin are generally determined by various chromatographic methods. Different approaches such as UV spectrophotometry (Mabry et al. 1970; Macheix et al. 1990) 
gas chromatography (GC), capillary electrophoresis (CE), high-pressure liquid chromatography (HPLC), thin layer chromatography (TLC), and high-performance thin layer chromatography (HPTLC) are some of the frequently used methods for the detection, qualitative analysis, and quantification (Sharma et al. 2007).

Spectrophotometric methods are used for identification of phenolic acids and are generally carried between a range of 220 to $320 \mathrm{~nm}$ (Mabry et al. 1970; Macheix et al. 1990); however, methods such as the Folin Ciocalteu spectrophotometric method results in nonspecific detection of the phenolic compounds and the interference of components such as ascorbic acid in food samples, that behave as reducing agents. Absorption of phenolic compounds is affected by $\mathrm{pH}$, solvents used in the method and the interference of proteins and amino acids (Constantine et al. 2007).

Volatile compounds are directly analyzed by gas chromatography, a technique of unsurpassed separation capacity (Sostaric et al. 2000). GC is a major chromatographic technique employed for the analysis of essential phenolic acids in plants. It deals with high sensitivity and selectivity (Chiou et al. 2007) but requires derivatization step of hydroxyl groups in phenolic compounds. They are modified by various reagents to make more volatile compounds by a process such as methylation, conversion into trimethylsilyl (TMS) derivatives. However, problems such as poor separation and low stability after derivatization state are some of the shortcomings of this method. CE is too employed for analysis of phenolic compounds (Huck et al. 2005; Butehorn et al. 1996). Mostly, the method falls in the field of natural product research, including the analysis of plants, vegetables, herbs, and other plant- or fruit-derived products. It results in oxidation of phenolic compounds by dissolved oxygen and increase in migration time of flavonoids due to the increase in buffer concentrations (Constantine et al. 2007).

TLC methods have the ability to screen phenolic compounds easily (Tilay et al. 2008). The results obtained by TLC method are generally quantified using more multifaceted techniques like HPTLC (Mabinya et al. 2006). However detection of vanillin by spraying with 2, 4dinitrophenylhydrazine (2, 4-DNPH) is not significant as the peaks are not detected properly. Currently, the main qualitative and quantitative techniques for phenolic compound detection are HPLC (Rao et al. 1999; Zheng et al. 2007). The European pharmacopoeia suggests the development of such analytical method which demands the adequate amount of reagents, solvents, and material (European Pharmacopoeia 2008). HPTLC allows for the simultaneous analysis of large sample size using small quantities of solvents, thus reducing time and cost of the analysis. The sensitivity for phenolic compounds performed by HPTLC is more as compared to HPLC (Prinjaporn et al. 2013). Mobile phase having pH 8 and above can be employed. Sample with turbidity and different combinations of solvent can be directly applied. It facilitates automated application and repeated scanning of the chromatogram with the same or different parameters (Bakshi et al. 2002). Therefore, this technique should be taken into consideration as an alternative to HPLC.

HPTLC is a sophisticated instrumental technique which allows a fast and inexpensive method for analysis. Special advantage of HPTLC includes high sample throughput and low cost per analysis. HPTLC offers a great variety of stationary phases with unique selectivity for mixture components and their separation simultaneously. Processing of standards and samples identically on the same plate directs to better accuracy and precision of method for assessment. HPTLC development is extensive as the mobile phases are fully evaporated before the detection step thus preventing solvent interference in analysis. It minimizes exposure risks and significantly discarding toxic organic effluent problems were reduced thereby reducing possibilities of environment pollution. In response to this, HPTLC-based methods could be considered as a good alternative as they are being explored as an important tool in routine analysis. The HPTLC-developed method is actively used in application of qualitative and quantitative analyses of a wide range of compounds, such as herbal and botanical dietary supplements and nutraceuticals. It helps in identifying compounds present in a given substance; to check starting raw materials (plant extracts, extracts of animal origin, fermentation mixtures) identification of drugs and their metabolites in biological media such as urine, plasma, or gastric fluid (pharmacological, toxicological, pharmacokinetic) (Renger 1993; 1998).

The aim of the present study is to develop rapid, economic, selective HPTLC method for analysis and simultaneous determination of FA and vanillin with proper peak separation and hence can be used for routine high-throughput detection and determination of phenolic compounds. It is a onestep biotransformation process using culture Pycnoporus cinnabarinus which undergoes propenoic acid chain degradation of FA to vanillin (Tilay et al. 2008).

\section{Methods}

\section{Chemicals/Reagents}

Standard FA and vanillin (99\% purity), maltose, diammonium tartarate, yeast extract, malt extract, potassium dihydrogen orthophosphate, magnesium sulfate, calcium chloride, thiamine hydrochloride, sodium hydroxide, and agar powder were procured from Hi-Media Laboratory (Mumbai, India). HPLC grade toluene, 1, 4-dioxan, acetic acid, ethyl acetate, and methanol were procured from Hi-Media (Mumbai, India).

\section{Instrumentation}

CAMAG TLC system consist of a CAMAG Linomat V (Muttenz, Switzerland) sample applicator and CAMAG 


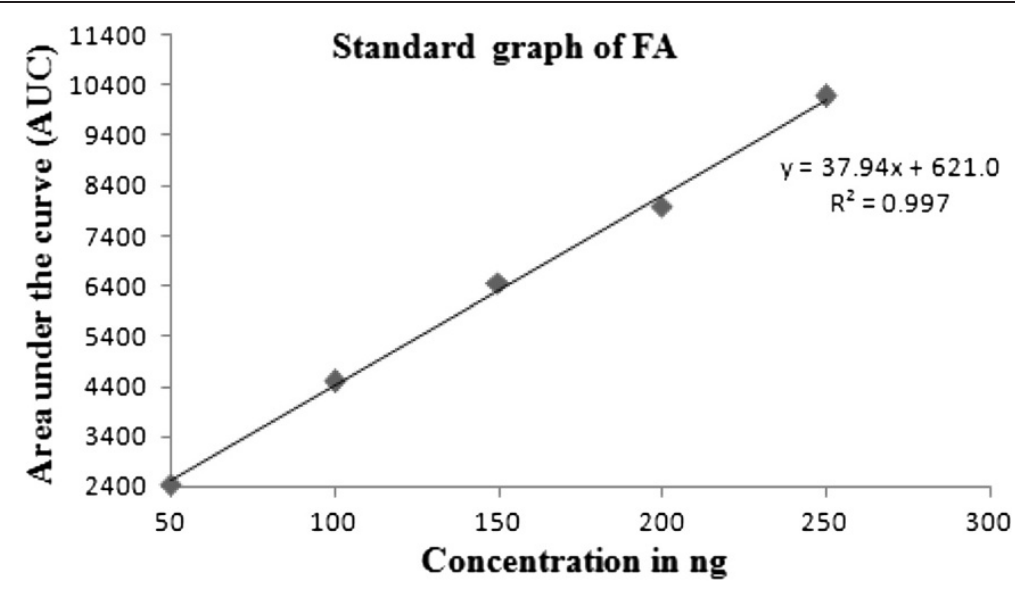

Figure 1 Standard graph of FA by HPTLC method.

TLC Scanner 3 controlled by WinCats software (1.4.3.6336); CAMAG glass twin-trough chambers $\left(20 \times 10 \times 4 \mathrm{~cm}^{3}\right)$; $100-\mu l$ Hamilton syringe; Silica gel plates $\left(\mathrm{G}_{60} \mathrm{~F}_{254}, 20 \times\right.$ $10 \mathrm{~cm}$ ) were procured from E-Merck Pvt. Ltd., Mumbai, India. For extraction of vanillin, Buchi evaporator system was used consisting of Buchi evaporator R-124, Buchi water bath B-480, and Buchi vacuum controller B-721.

\section{Preparation of stock solution}

Standard stock solutions were prepared by dissolving $25 \mathrm{mg}$ of vanillin and $25 \mathrm{mg}$ of FA in $25 \mathrm{ml}$ of methanol. Working standard solution was diluted (1:200) from stock solution of FA and vanillin to attain concentration of $5 \mu \mathrm{g} / \mathrm{ml}$.

\section{Microorganism}

Pycnoporus cinnabarinus NCIM 1181 was procured from National Centre for Industrial Microorganism (NCIM), National Chemical Laboratory (NCL), Pune, India. Culture was maintained on potato dextrose agar slants at $4^{\circ} \mathrm{C}$.

\section{Media for vanillin production}

A production media consisting of maltose $20 \mathrm{~g} / \mathrm{l}$, diammonium tartarate $1.8415 \mathrm{~g} / \mathrm{l}, \mathrm{KH}_{2} \mathrm{PO}_{4} 0.2 \mathrm{~g} / \mathrm{l}, \mathrm{CaCl}_{2} 2 \mathrm{H}_{2} \mathrm{O}$ $0.0132 \mathrm{~g} / \mathrm{l}, \mathrm{MgSO}_{4} \cdot 7 \mathrm{H}_{2} \mathrm{O} 0.5 \mathrm{~g} / \mathrm{l}$, yeast extract $0.5 \mathrm{~g} / \mathrm{l}$, and thiamine hydrochloride $2.5 \mathrm{mg} / \mathrm{l}$ was adjusted to $\mathrm{pH} 7$ and inoculated using mycelium fragments of $P$. cinnabarinus (Gross et al. 1993). This was further incubated on an incubator shaker $(150 \mathrm{rpm})$ at $37^{\circ} \mathrm{C}$ for 6 days. After 3 days of growth, sterile solution of FA $(0.03 \mathrm{~g} / 100 \mathrm{ml})$ was added to the media prepared by dissolving FA in $0.1 \mathrm{~N} \mathrm{NaOH}$ in the form of sodium ferulate.

\section{Extraction of FA and vanillin from the culture media}

The broth obtained after fermentation was filtered and the filtrate was acidified to obtain a $\mathrm{pH}$ of 1 to $2.80 \mathrm{ml}$ of the above acidified solution was extracted thrice with equal volume of ethyl acetate. The extracts and the residue were redissolved in $50 \%(v / v)$, respectively. The organic phase containing FA and vanillin was concentrated (up to 2 to $3 \mathrm{ml}$ ) using a rotary vacuum

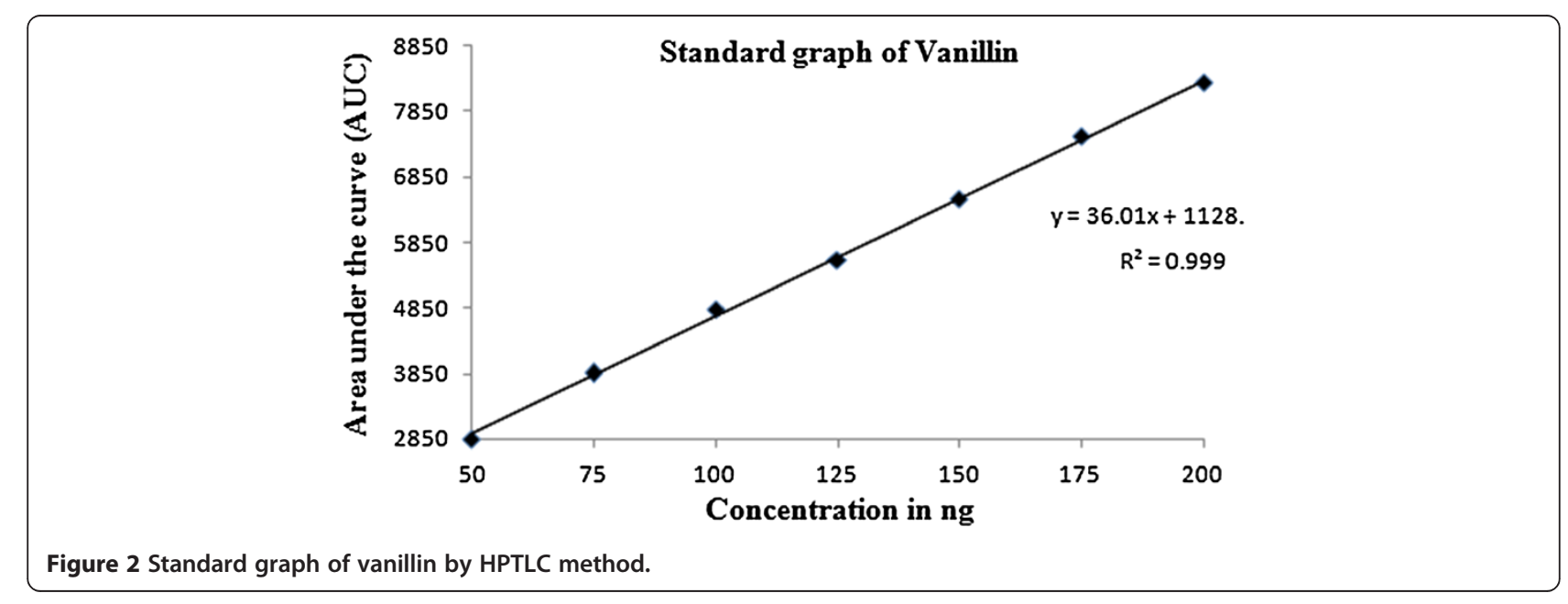


Table 1 Intra- and inter-day precision $(n=5)$

\begin{tabular}{|c|c|c|c|c|c|}
\hline \multirow[t]{2}{*}{ Compound } & \multirow{2}{*}{$\begin{array}{l}\text { Std amount } \\
\text { (ng/band) }\end{array}$} & \multicolumn{2}{|c|}{ Intra-day precision } & \multicolumn{2}{|c|}{ Inter-day precision } \\
\hline & & $\overline{S D^{a}}$ & $\% \mathrm{RSD}^{\mathrm{b}}$ & $\overline{S D^{a}}$ & \%RSD $^{\mathrm{b}}$ \\
\hline \multirow[t]{3}{*}{ Ferulic acid } & 100 & 4.52 & 0.021 & 1.64 & 0.053 \\
\hline & 150 & 2.93 & 0.015 & 4.66 & 0.091 \\
\hline & 200 & 4.51 & 0.001 & 4.57 & 0.050 \\
\hline \multirow[t]{3}{*}{ Vanillin } & 100 & 2.09 & 0.044 & 2.21 & 0.040 \\
\hline & 150 & 2.97 & 0.048 & 2.77 & 0.042 \\
\hline & 200 & 1.93 & 0.022 & 2.02 & 0.023 \\
\hline
\end{tabular}

$\overline{\mathrm{SD}}$, standard deviation $(n=5) ; \mathrm{RSD}$, percent relative standard deviation $(n=5)$.

evaporator with conditions $\left(55^{\circ} \mathrm{C}, 150 \mathrm{rpm},<80 \mathrm{mbar}\right)$ followed by reconstitution in $2 \mathrm{ml}$ of methanol $50 \%$ $(v / v)$ (Tilay et al. 2010). This solution was used for quantification of FA and vanillin by HPTLC.

\section{Instrumentation and chromatographic parameters}

HPTLC was executed using silica gel $60 \mathrm{~F}_{254}$ plates. A $10 \mu \mathrm{l}$ of standard working solutions of FA and vanillin were applied to the plates of size $20 \times 10 \mathrm{~cm}$ with a $5-\mathrm{mm}$ band length. Ascending chromatography silica gel plate development traveled to a distance of $85 \mathrm{~mm}$ at temperature of $25^{\circ} \mathrm{C}$ with toluene/1, 4-dioxan/acetic acid $(9: 2.5: 0.4 ; v / v)$ as mobile phase. After development, the plates were dried and chromatograms were recorded at 320 and $312 \mathrm{~nm}$, respectively using CAMAG TLC Scanner 3. Quantitative evaluation was performed with WinCats software using deuterium lamp having slit width of $5 \times 0.45 \mathrm{~mm}$ and an application rate of $150 \mathrm{~nL} / \mathrm{s}$.

\section{Validation of method}

Validation was performed in terms of linearity, specificity, precision, limit of detection (LOD), limit of quantification (LOQ), robustness, and system suitability by $\mathrm{ICH}$ guidelines (CPMP/ICH/381/95).

\section{Linearity}

Standard solution of FA (50 to $250 \mathrm{ng} / \mathrm{band}$ ) and vanillin (50 to $200 \mathrm{ng} /$ band) with varying volumes were applied on TLC plates. A plot of peak area against concentrations and its respective standard deviation (SD) and coefficient of correlation was calculated for both the compounds.

\section{Precision}

Precision specifies random errors. Results were expressed in percent relative standard deviation $(\% \mathrm{RSD}<2)$. Standard solution of FA (100, 150, and $200 \mathrm{ng} / \mathrm{band})$ and of vanillin (100, 150, and $200 \mathrm{ng} / \mathrm{band})$ were applied. Intra-day precision was evaluated by applying each concentration five times on the same day. Inter-day precision was evaluated by applying each concentration five times on three different days with an interval of $24 \mathrm{~h}$.

\section{Recovery}

The recovery was used to determine the accuracy of the method. Recovery of FA and vanillin with three different concentration namely, 50, 100, and $150 \mathrm{ng}(n=3)$ was performed. Samples after extraction were spiked with standard concentration and applied. Peak areas of standard added to samples were calculated and average percent recovery was estimated. Further average percent recovery was calculated.

\section{Specificity}

Specificity was performed to compare the standard FA and vanillin and extract. It was calculated by comparing the Rf of the peak, peak start, peak apex, and peak end of the standard and extract. The spectral scan of both the standard and extract was compared. Spectrum scan accelerated at $100 \mathrm{~nm} / \mathrm{s}$ with split dimensions $5 \times 0.45 \mathrm{~mm}$, micro. Spectral detection for optimum wavelength was calculated in the range 200 to $700 \mathrm{~nm}$.

\section{Robustness}

Modifications in mobile phase concentration, mobile phase volume, mobile phase saturation time, and temperature were examined to check the robustness. Standard solutions of FA (150 ng/band) and vanillin (150 ng/band) were applied thrice and \%RSD of each compound was calculated.

\section{Limit of detection and limit of quantification}

LOD is the lowest amount of compound that can be detected with signal-to-noise ratio of 3:1 and LOQ is the lowest amount of compound which can be quantified by signal-to-noise ratio 10:1 with adequate precision and

Table 2 Recovery of FA and vanillin

\begin{tabular}{|c|c|c|c|c|c|c|}
\hline Sample & Amount in sample (ng) & Std added (ng) & Total conc. (ng) & Recovery (ng) & \%Recovery & Avg. \%Recovery \\
\hline \multirow[t]{3}{*}{$\overline{F A}$} & 20.54 & 50 & 70.54 & $69.20 \pm 0.30$ & $98.47 \pm 0.05$ & 98.77 \\
\hline & 20.54 & 100 & 120.54 & $119.23 \pm 2.2$ & $99.10 \pm 1.89$ & \\
\hline & 20.54 & 150 & 170.54 & $168.42 \pm 0.29$ & $98.56 \pm 0.17$ & \\
\hline \multirow[t]{3}{*}{ Vanillin } & 37.23 & 50 & 87.23 & $84.08 \pm 0.38$ & $96.51 \pm 0.34$ & 98.45 \\
\hline & 37.23 & 100 & 137.23 & $136.15 \pm 0.45$ & $99.19 \pm 0.30$ & \\
\hline & 37.23 & 150 & 187.23 & $186.49 \pm 2.30$ & $99.65 \pm 1.25$ & \\
\hline
\end{tabular}

Mean \pm standard deviation $(n=3)$. 


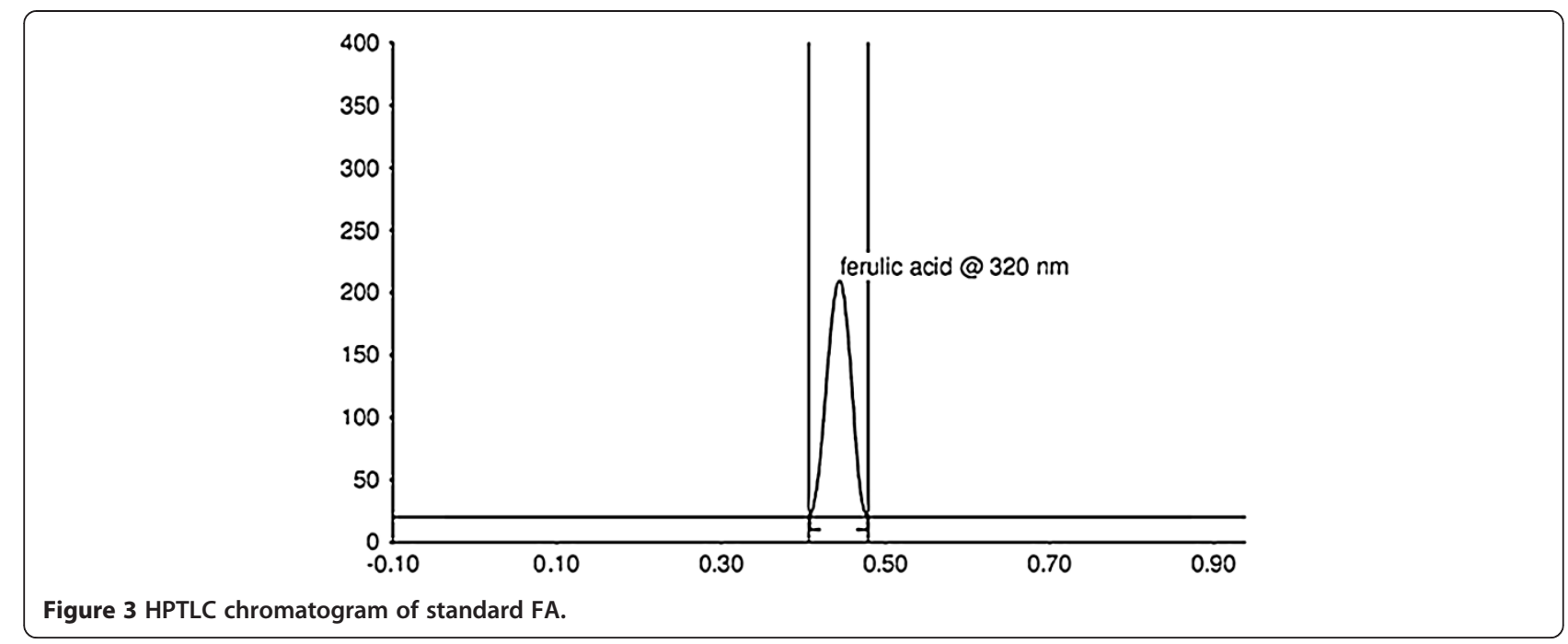

specificity. LOD and LOQ of FA and vanillin were calculated.

\section{System suitability}

System suitability was executed to check the reproducibility and resolution of the method. Standard solution of both the standards of $150 \mathrm{ng}$ concentration $(n=5)$ was analyzed on the same chromatographic plates. After development, plates were scanned and the peak area of each concentration and their $\mathrm{Rf}$ values were calculated.

\section{Results and discussion}

A GC method for detection of phenolic compounds is complicated and unsuitable for rapidly analyzing profuse samples and with derivatization step. HPLC-ECD, a new method was developed for the analysis of phenolic compound. However, use of HPLC with ECD is not feasible as a routine analytical method (Takahashi et al. 2013). Even with the HPLC UV detector system, the analysis is time consuming and the quantity of the solvents is the main concern. In the present study, two compounds FA and its bio-transformed product vanillin were quantified using HPTLC. Various mobile phases were screened for proper separation of both the compounds. Well-defined peaks with Rf values 0.48 for FA and 0.56 for vanillin were obtained using toluene/1, 4-dioxan/acetic acid $(9: 2.5: 0.4 ; v / v)$ (Olsson et al. 1974). Experimental conditions should be selected when the compounds to be analyzed moves towards or near to the center of the layer $(R f=0.5)$

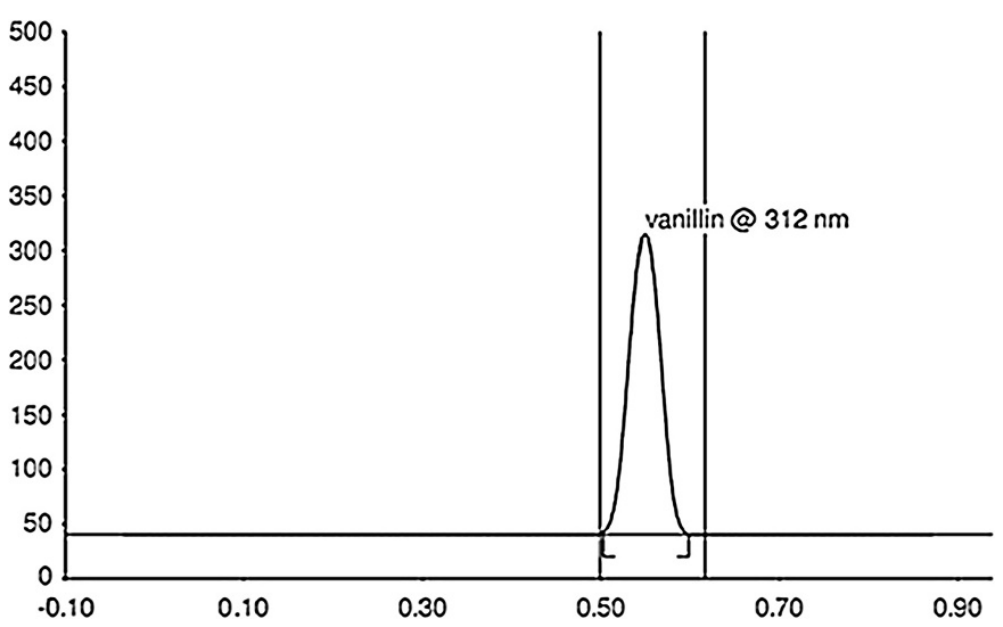

Figure 4 HPTLC chromatogram of standard vanillin. 


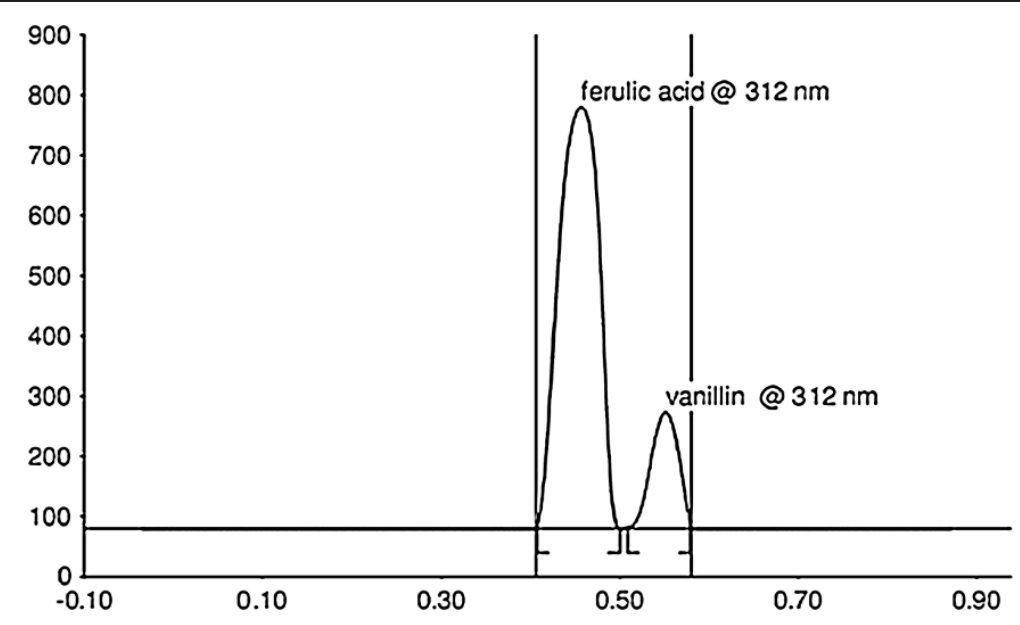

Figure 5 HPTLC chromatogram of FA and vanillin present in crude extract.

(Srivastava 2011). Krishna veni et al. (2013) used methanol/ water/glacial acetic acid $(20: 5: 2 ; v / v)$ as the mobile phase and resulted with Rf 0.84 for vanillin. For better peak detection and Rf, the polarity can be reduced. Other mobile phases were compared which resulted in tailing of peaks (Sharma et al. 2007) using methanol/ water/isopropanol/acetic acid (30:65:2:3; $v / v)$ and inappropriate separation of both the compounds with toluene/ethyl acetate/formaldehyde $(6: 3: 1 ; v / v)$ (Srivastava et al. 2008), no identification of vanillin peak using hexane/ethyl acetate $(5: 2 ; v / v)$ (Hennig et al. 2011) and 1-butanol/ acetic acid/water (66:17:17; v/v) (Males et al. 2001). Chloroform/methanol/formic acid $(85: 15: 1 ; v / v)$ with spraying reagent 2, 4-dinitrophenylhydrazine was used for vanillin detection but resulted in poor peak visualization and separation of vanillin (Mabinya et al. 2006). Sharp peaks were obtained with a presaturation of mobile phase for $20 \mathrm{~min}$. FA and vanillin was quantified using UV detector and scanning at 320 and $312 \mathrm{~nm}$. The peaks corresponding to FA and vanillin in samples had the same retention time when compared to their respective standards.

\section{Linearity}

Linearity was achieved with concentrations ranging from 50 to $250 \mathrm{ng} / \mathrm{band}$ for FA and 50 to $200 \mathrm{ng} / \mathrm{band}$ for vanillin (Figures 1 and 2). The regression equation and correlation coefficient of FA was found to be $y=37.94 \times X+621.04$, $R^{2}=0.9975$ with $\mathrm{SD}=1.95 \%$ and for vanillin $y=36.016 \times$ $X+1128.3, R^{2}=0.9991$ with $\mathrm{SD}=1.60 \%$.

\section{Precision}

To get accurate chromatographic results, the precision of the chromatographic method must be analyzed and confirmed whether it is fit for purpose which is adequate to the analytical requirements and it is evaluated in terms of intra- and inter-day precision. The standard deviation and percent relative standard deviation will evaluate the variation limit of the analysis. The value lower than $2 \%$ indicate the method is more precise to variation which assumes that the chromatograph does not malfunction after the system precision testing has been performed (Indrayanto 2011). Peak areas measurement of 100, 150, and $200 \mathrm{ng}$ concentration of FA and vanillin showed \%RSD less than 2 as shown in Table 1. Both intra- and inter-day results suggested an excellent method of precision which ensures the objective of the method development phase to be reproducible.

\section{Recovery}

Recovery is an important parameter as it offers information about the recovery of the analyte from the sample preparation and the effect of matrix. If the recovery is close to $100 \%$ then it implies that the proposed analytical method is free from constant and proportional systematic error (Srivastava 2011). Recovery of FA at three different levels obtained was $98.47 \%, 99.1 \%$, and 98.75\% with $98.77 \%$ average recovery and of vanillin was $96.51 \%, 99.19 \%$, and $99.65 \%$ with $98.45 \%$ average

Table 3 Specificity of FA and vanillin

\begin{tabular}{llll}
\hline Retention factor (Rf) & Peak start & Peak apex & Peak end \\
\hline FA $^{a}$ & 0.43 & 0.48 & 0.51 \\
Vanillin $^{\mathrm{a}}$ & 0.49 & 0.56 & 0.62 \\
FA $^{\mathrm{b}}$ & 0.41 & 0.47 & 0.50 \\
Vanillin $^{\mathrm{b}}$ & 0.51 & 0.56 & 0.60 \\
\hline
\end{tabular}

${ }^{\mathrm{a}}$ Standard ferulic acid and vanillin; ${ }^{\mathrm{b}}$ crude extracts. 


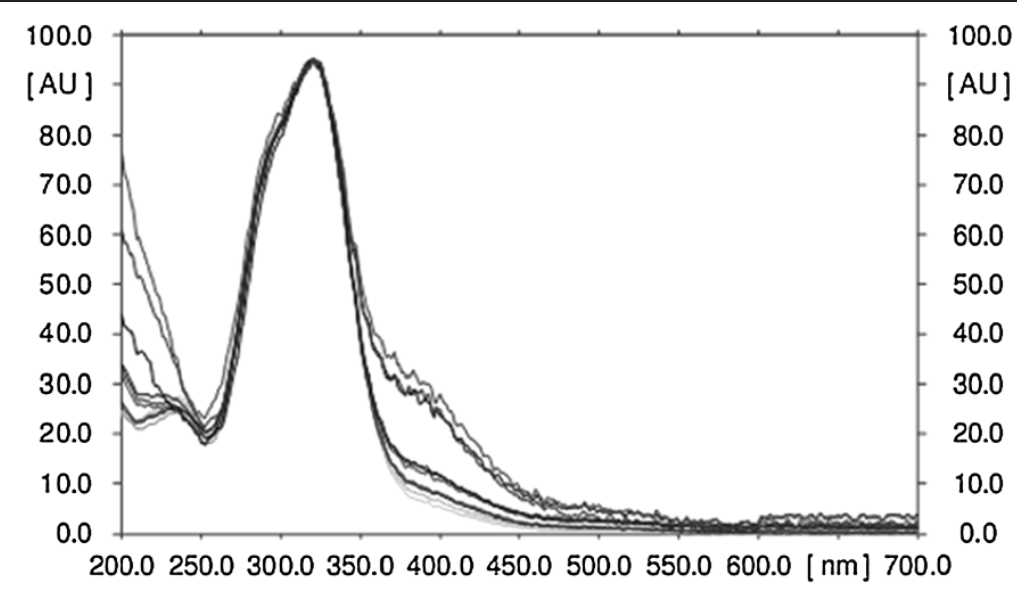

Figure 6 Overlay of UV absorption spectra of standard FA with crude extract.

recovery. The results are shown in Table 2. The percentage recovery was close to $100 \%$ which indicated no interference of any other compound and representing the accuracy of the method. This indicates the suitability of the method for the routine analysis.

\section{Specificity}

Specificity is a method which provides a response for only a single analyte. This study is performed to check how accurately and specifically the analyte of interest is estimated in the presence of other components with system interference during detection and quantification of analyte (Indrayanto and Yuwono 2010; Kakde et al. 2008). Retention factor values of standard FA and vanillin were compared with sample extract. There was no interference of other peaks as shown in Figures 3, 4, and 5. The standard and sample was compared with respect to peak start, peak apex, and peak end of the bands which showed the specificity between extracts and standard compound and purity of the peaks (Table 3). Overlay of the standard and sample compound using spectral scan was compared to confirm the specificity (Figures 6 and 7). Spectral scan of both the compounds showed maximum absorption at $320 \mathrm{~nm}$ for ferulic acid and $312 \mathrm{~nm}$ for vanillin. Thus, results obtained from comparison of peak and spectral scan showed the method is specific for detection of FA and vanillin.

\section{Robustness}

Robustness can be described as the ability to reproduce the analytical method under different circumstances and provides an indication of its reliability during normal phase. It was introduced to avoid problems in

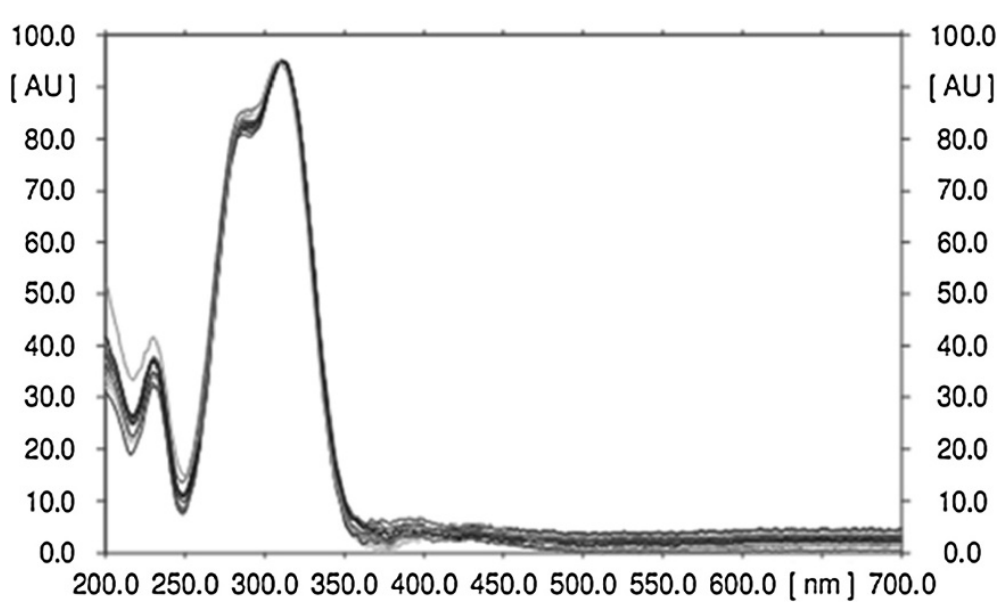

Figure 7 Overlay of UV absorption spectra of standard vanillin with crude extract. 
Table 4 Robustness of FA \& Vanillin

\begin{tabular}{|c|c|c|c|c|}
\hline \multirow[t]{2}{*}{ Parameters } & \multicolumn{2}{|l|}{ FA } & \multicolumn{2}{|l|}{ Vanillin } \\
\hline & $S D^{a}$ & $\% \mathrm{RSD}^{\mathrm{b}}$ & $\mathrm{SD}^{\mathrm{a}}$ & $\% \mathrm{RSD}^{\mathrm{b}}$ \\
\hline Mobile phase (toluene/1,4-dioxan/acetic acid) $(9\{ \pm 1\}: 2.5\{ \pm 1\}: 0.4\{ \pm 0.2\})(\mathrm{V} / \mathrm{V})$ & $2.95 \pm 0.13$ & 0.039 & $2.526 \pm 0.05$ & 0.039 \\
\hline Mobile phase vols. 10, 12 and $14 \mathrm{ml}$ & $3.00 \pm 0.09$ & 0.027 & $3.626 \pm 0.12$ & 0.056 \\
\hline Saturation time 10, 15 and $20 \mathrm{~min}$ & $2.20 \pm 0.06$ & 0.027 & $2.699 \pm 0.07$ & 0.058 \\
\hline Temperature 25,30 and $37^{\circ} \mathrm{C}$ & $2.25 \pm 0.12$ & 0.050 & $3.351 \pm 0.10$ & 0.052 \\
\hline
\end{tabular}

${ }^{\mathrm{a}} \mathrm{SD}$, standard deviation of peak area $(n=3) ;{ }^{\mathrm{b} S D}$, percent relative standard deviation $(n=3)$.

inter-laboratory studies and to discover the potentially repairable factors (Van der Hyden et al. 2001). According to the ICH guidelines, the evaluation of robustness should be considered during the development phase and depends on the type of procedure under study. For robustness evaluation by chromatographic method, the acceptance criteria are that, the Rf values of all standards should lie within the acceptance criteria of the precision method by performing variations in considered parameters. Calculations of standard or relative error are common ways to look at the data and departures from deviations in the data will directly affect robustness. Variations made in mobile phase composition, mobile phase volume, saturation time, and temperature showed less \%RSD and SD for FA and vanillin by spotting $150 \mathrm{ng} /$ spot $(n=3)$ (Table 4). No significant change in Rf or response to FA and vanillin was observed which indicated robustness of the method. Robustness study has provided valuable information about the quality and reliability of the method and no further development or optimization is necessary.

\section{Limit of detection and limit of quantification}

LOD is based on the analyte response sensitivity (response per amount or concentration per time, using either peak height or area), and LOQ is the lowest amount of analyte that can be quantitatively determined in sample with defined precision and accuracy under standard conditions. LOQ is usually a multiple of LOD (Kakde et al. 2008). Standard deviation and slope used in the equations are used to determine LOD and LOQ which is equivalent to instrument sensitivity for the specific analyte, reinforcing that the LOD/LOQ details, are expressed in units of analyte concentration (Apostol et al. 2012). It is important to determine sensitivity using analyte amounts near to their detection limits. LOD and LOQ with signal-to-noise ratio of FA were found to be 13.63 and $45.42 \mathrm{ng} / \mathrm{band}$, respectively. LOD and LOQ of vanillin were found to be 10.59 and $35.30 \mathrm{ng} / \mathrm{band}$, respectively. Sensitivity of the method is evaluated with regard to LOD and LOQ (Kakde et al. 2008). These results indicate the sensitivity of the method which can be used for quantification of the compound.

\section{System suitability}

System suitability test (SST) is an integral part of many analytical procedures. The test is based on the conception that, the equipment, electronics, analytical operations, and samples to be analyzed represent an integral system that can be evaluated. System suitability test parameters to be established for a particular procedure depend upon the type of procedure being validated. It is the ability of the analytical method to detect analyte quantitatively in the presence of other components which are expected to be present in the sample and they should be chromatographed along with the analyte to check the system suitability and retention factor of the required analyte (Dolan 2004). On the basis of repeatability relative standard deviations of peak response, SST was analyzed. Retention factor of FA and vanillin were 0.48 and 0.56 , respectively. Standard deviation of FA was $2.95 \pm 0.13$ with $0.039 \%$ RSD and standard deviation of vanillin was $3.62 \pm 0.12$ with $0.056 \%$ RSD. The low \%RSD indicates the reproducibility and the system suitability of the method.

\section{Conclusion}

The simultaneous detection of FA and vanillin by the HPTLC method can be performed as there is noteworthy difference in their retention factor values. The proposed method was developed and validated by ICH guidelines which is simple, rapid, accurate, precise, sensitive, and eco-friendly. The mobile phase selected was toluene/1, 4dioxan/acetic acid 9:2.5:0.4 $(v / v)$ which resulted in proper peak separation as compared to different mobile phase which were not able to separate the compounds properly. Other chromatographic methods like HPLC, GC, and spectrophotometric mentioned may not be applied for routine check because of the various shortcomings as compared to HPTLC. The total optimized method is therefore useful in both qualitative and quantitative analysis for routine assays in pharmaceutical and food industry within acceptable limits.

Competing interests

The authors declare that they have no competing interests. 


\section{Authors' contributions}

SH and SD has performed all the experimental and analytical work and drafted the manuscript. The guidelines for all the mentioned part was provided by UA. All authors read and approved the final manuscript.

Received: 27 October 2013 Accepted: 5 February 2014

Published online: 01 April 2014

\section{References}

Apostol I, Krull I, Kelner D (2012) Analytical Method Validation for Biopharmaceuticals. Analytical Chemistry. doi:10.5772/52561

Bakshi M, Singh SJ (2002) Development of validated stability-indicating assay methods-critical review. J Pharm Biomed Anal 28:1011-1040

Butehorn U, Pyell U (1996) Micellar electrokinetic chromatography as a screening method for the analysis of vanilla flavorings and vanilla extracts. J Chromatogr A 736:321-332

Chiou A, Karathanos VT, Mylona A, Salta FN, Preventi F, Andrikopoulos NK (2007) Currants (Vitisvinifera L.) content of simple phenolic and antioxidant activity. Food Chem 102:516-522

Constantine DS (2007) Extraction, separation, and detection methods for phenolic acids and flavonoids. J Sep Sci 30:3268-3295

Dolan JW (2004) System suitability. LC troubleshooting, BASi Northwest Laboratory, McMinnville, Oregon, USA 17(6):328-332

European Pharmacopoeia (EDQM) (2008) 6th edn. Strasbourg, Council of Europe

Graf E (1992) Antioxidant potential of ferulic acid. Free Radical Biol Med 13:435-448

Gross B, Asther M, Corrieu G, Brunerie P (1993) Production of vanillin by bioconversion of benzenoid precursors by Pycnoporus. U.S. Patent 5262315 B

Hennig L, Garcia GM, Giannis A, Bussmann RW (2011) New constituents of Baccharis genistelloides (Lam.). Pers. Arkivoc 6:74-81

Ho K, Yazana LS, Ismail N, Ismail M (2009) Apoptosis and cell cycle arrest of human colorectal cancer cell line HT-29 induced by vanillin. Cancer Epidem 33:155-160

Huck CW, Stecher G, Scherz H, Bonn G (2005) Analysis of drugs, natural and bioactive compounds containing phenolic groups by capillary electrophoresis coupled to mass spectrometry. Electrophoresis 26:1319-1333

Indrayanto G (2011) Analytical Aspects of High Performance Thin Layer Chromatography. MM. Srivastava edn, High-Performance Thin-Layer Chromatography (HPTLC), Springer-Verlag Berlin Heidelberg

Indrayanto G, Yuwono MS (2010) TLC: Validation of Analyses. In. Cazes J Encyclopedia of Chromatography, 3rd edn, Taylor \& Francis Group, London

Kakde RB, Kotak VH, Kale DL (2008) Estimation of bisoprolol fumarate in pharmaceutical preparations by HPTLC. Asian J Res Chem 1(2):70-73

Krishna Veni N, Meyyanathan SN, Reddy AA, Sompura SA, Elango K (2013) Analysis of Vanillin In Food Products By High Performance Thin Layer Chromatography. J Adv Sci Res 4(1):48-51

Lomascolo A, Stentelaire C, Asther M, Lesage-Meessen L (1999) Basidiomycetes as new biotechnological tools to generate natural aromatic flavours for the food industry. Trends Biotechnol 17:282-289

Mabinya LV, Mafunga T, Brand JM (2006) Determination of ferulic acid and related compounds by thin layer chromatography. Afr J Biotechnol 5:1271-1273

Mabry TJ, Markham KR, Thomas MB (1970) The Systematic Identification of Flavonoids, 1st edition. Springer, New York, NY, USA

Macheix JJ, Fleuriet A, Billot J (1990) Fruit Phenolics. CRC Press, Bota Raton, FL

Males Z, Medic-Saric M (2001) Optimization of TLC analysis of flavonoids and Phenolic acids of Helleborus atrorubens Waldst. et Kit. J Pharm Biomed Anal 24(3):353-9

Olsson L, Samuelson O (1974) Chromatography of aromatic acids and aldehydes and phenols on cross-linked polyvinylpyrrolidone. J Chromatogr 93:189-199

Priefert H, Rabenhorst J, Steinbuchel A (2001) Biotechnological production of vanillin. Appl Microbiol Biotechnol 56:296-314

Prinjaporn TN, Namthip N, Poomrat R, Weena S, Orawon C (2013) Simple and Rapid Determination of Ferulic Acid Levels in Food and Cosmetic Samples Using Paper-Based Platforms. Sensors 13:13039-13053

Raisi A, Aroujaliana A, Kaghazchia T (2008) Multicomponent pervaporation process for volatile aroma compounds recovery from pomegranate juice. Membr Sci 322:339-348

Rakchoy S, Suppakul P, Jinkarn T (2009) Antimicrobial effects of vanillin coated solution for coatingpaperboard intended for packaging bakery products. As J Food Ag-Ind 2:138-147
Rao SR, Ravishankar GA (1999) Biotransformation of isoeugenol to vanilla flavour metabolites and capsaicin in suspended and immobilized cell cultures of Capsicum frutescens: study of the influence of $\beta$-cyclodextrin and fungal elicitor. Process Biochem 35:341-348

Renger B (1993) Quantitative planar chromatography as a tool in pharmaceutical analysis. J AOAC Int 76:7-13

Renger B (1998) Contemporary thin layer chromatography in pharmaceutical analysis. J AOAC Int 81:333-339

Sharma UK, Sharma N, Gupta AP, Kumar V, Sinha AK (2007) RP-HPTLC densitometric determination and validation of vanillin and related Phenolic compounds in accelerated solvent extract of Vanilla planifolia. J Sep Sci 30:3174-3180

Sostaric T, Boyce MC, Spickett EE (2000) Analysis of volatile components in vanilla extract and flavorings by solid-phase microextraction and gas chromatography. J Agric Food Chem 48:5802-5807

Srivastava MM (2011) An Overview of HPTLC. In: A Modern Analytical Technique with Excellent Potential for Automation, Optimization, Hyphenation, and Multidimensional Applications. High-Performance Thin-Layer Chromatograpy (HPTLC), Springer-Verlag Berlin Heidelberg

Srivastava SK, Singh AP, Rawat AKS (2008) Pharmacognostical and phytochemical evaluation of Lycopodium clavatum stem. J Sci Ind Res 67:228-232

Takahashi M, Sakamaki S, Fujita A (2013) Simultaneous analysis of Guaiacol and vanillin in a vanilla extract by using High Performance Liquid Chromatography with Electrochemical detection. Biosci. Biotechnol. Biochem 77(3):595-600

Tilay A, Bule M, Kishenkumar J, Annapure U (2008) Preparation of ferulic acid from agricultural wastes: its improved extraction and purification. J Agric Food Chem 56:7644-8

Tilay A, Bule M, Annapure U (2010) Production of Biovanillin by One-Step Biotransformation Using Fungus Pycnoporous cinnabarinus. J Agric Food Chem 58:4401-4405

Van der Hyden Y, Nijhuis A, Smayers-Verbeke J, Vandeginste BMG, Massart DL (2001) Guidance for robustness/ruggedness test in method validation. J Pharm Biomed Anal 24:723-753

Wu SL, Chen JC, Li CC, Lo HY, Ho TY, Hsiang CY (2009) Vanillin Improves and Prevents Trinitrobenzene Sulfonic Acid-Induced Colitis in Mice. J Pharmacol Exp Ther 330:370-376

Xu F, Sun RC, Sun JX, Liu CF, Heb BH, Fan JS (2005) Determination of cell wall ferulic and p-coumaric acids in sugarcane bagasse. Anal Chim Acta 552:207-217

Zheng L, Zheng P, Sun Z, Bai Y, Wang J, Guo X (2007) Production of vanillin from waste residue of rice bran oil by Aspergillus niger and Pycnoporus cinnabarinus. Bioresour Technol 98:1115-1119

doi:10.1186/s40543-014-0021-6

Cite this article as: Hingse et al: Method development for simultaneous detection of ferulic acid and vanillin using high-performance thin layer chromatography. Journal of Analytical Science and Technology 2014 5:21

\section{Submit your manuscript to a SpringerOpen ${ }^{\odot}$ journal and benefit from:}

- Convenient online submission

Rigorous peer review

- Immediate publication on acceptance

- Open access: articles freely available online

- High visibility within the field

- Retaining the copyright to your article

Submit your next manuscript at $>$ springeropen.com 